\title{
La presencia de Juan de Mena en el Cancionero Musical de la Colombina ms. 7-1-28 (A propósito de Vuestros ojos que miraron) ${ }^{1}$
}

\author{
Ester Lidia Cicchetti \\ Università degli Studi dell'Aquila
}

Título: La presencia de Juan de Mena en el Cancionero Musical de la Colombina ms. 7-1-28 (A propósito de Vuestros ojos que miraron).

Resumen: El Cancionero musical (ms. 7-1-28) de la Biblioteca Colombina de Sevilla recoge una de las colecciones más antiguas y célebres de polifonía profana de finales del siglo XV, obra de músicos como Triana y Cornago y de poetas de las prendas de Mena y Santillana. En este trabajo me he atenido a reflexionar sobre unas coplas anónimas e incompletas añadidas por otra mano en el f. $6^{\mathrm{r}}$, justo detrás del villancico Gentil dama, musicado por Cornago. El cotejo con el resto de la tradición ha permitido aclarar la configuración de dichos fragmentos, y en algunos casos incluso su autoría y la intención del copista. Entre ellos destaca la canción de Juan de Mena Vuestros ojos que miraron, de la que no conocemos su melodía. Sin embargo, no es arriesgado suponer que también esta pieza, como otras dos del cordobés que se copiaron en el cancionero, se haya difundido por medio del canto. A través del examen de las relaciones retóricas, métricas y tématicas entre el villancico de Cornago, la canción de Mena y el resto de textos ańadidos en el f. $6^{\mathrm{r}}$, sin música, podría confirmar la hipótesis de que estos fragmentos se cantaran como alternativa a la mudanza de Gentil dama.

Palabras clave: Poesía cancioneril, Música, Cancionero musical de la Colombina, Juan de Mena, Transmisión.

Fecha de recepción: 2/10/2018.

Fecha de aceptación: 10/10/2018.
Title: The Presence of Juan de Mena in the Cancionero Musical de la Colombina ms. 7-1-28 (About Vuestros ojos que miraron).

Abstract: The Cancionero musical (ms. 1.7.28) of Seville's Colombina Library includes one of the oldest and most famous collections of secular polyphony from the late $\mathrm{XV}^{\text {th }}$ century, by composers such as Triana and Cornago and poets such as Mena and Santillana. In this occasion I have ventured to offer a few reflections about some anonymous and incomplete stanzas added by another hand in the f. $6^{\mathrm{r}}$ of this songbook, after the villancico Gentil dama, set to music by Cornago. The comparison with the rest of the tradition has led to cast some light on the configuration of these fragments, in some occasions their authorship, and the intention of the copyist who inserted them. A prime example is Juan de Mena's song Vuestros ojos que miraron: although we don't know its melody, it isn't too speculative to suppose that this piece, like the other two by the same author copied in the songbook, has also been popularized in the sung form. Through the study of the rhetoric, metrics and thematic relationships between Cornago's villancico, Mena's poem and the other fragmentary texts added in the f. $6^{\mathrm{r}}$ without music, we could confirm the hypothesis that these fragments were sung as an alternative to the mudanza Gentil dama.

Key words: Cancioneril poetry, Music, Cancionero musical de la Colombina, Juan de Mena, Transmission

Date of Receipt: 2/10/2018.

Date of Approval: 10/10/2018.

1 Este artículo deriva de una comunicación presentada en el III Congreso Internacional 
La aproximación tradicional a los cancioneros musicales ibéricos ha solido brillar por su miopía. La desconfianza hacia los textos trasladados bajo los pentagramas ha inducido a los filólogos a dejar de lado, muy a menudo, estos repertorios; y también en la vertiente musicológica, fruto de un análogo repliegue hacia el interior del perímetro disciplinar, se ha optado generalmente por ignorar las variantes poéticas documentadas en la tradición literaria, sin contar las injustificadas contaminaciones generadas por la voluntad de subsanar las composiciones incompletas para ajustarlas a la medida melódica ${ }^{2}$.

Creo poder afirmar que, en este escenario de diálogos frustrados, la edición del repertorio ibérico del Cancionero de Montecassino (MA1) a cargo de la filóloga Paola Elia y el musicólogo Francesco Zimei ${ }^{3}$ ha marcado un hito metodológico. Los cancioneros musicales españoles del XV y del XVI, netamente minoritarios con respecto a los literarios, también por obvias razones socio-culturales ${ }^{4}$, representan una tradición extremadamente activa que es preciso sondear en paralelo a la vía de transmisión predominante, que, por supuesto, sigue siendo la literaria. Por esta razón, en su modélico estudio del repertorio ibérico de MA1, Elia y Zimei han afinado una técnica ecdótica interdisciplinar, conectando las variantes de la poesía cantada tanto con la incidencia de la tradición oral (que, por ejemplo, llevaba al copista a reproducir solo el incipit de poemas muy conocidos), como con la necesidad de adaptar algunas composiciones lite-

Cancionero de Baena, organizado por la Fundación Centro Documentación Juan Alfonso de Baena (Baena 26/02/2015 - 28/02/2015).

2 Virginie Dumanoir, "Melodía y texto. El caso de los romances viejos", en Música y literatura en la España de la Edad Media y del Renacimiento, Madrid, Casa de Velázquez, 2003, pp. 107-116.

3 Paola Elia y Francesco Zimei, "Le ragioni di un approccio interdisciplinare", en $I l$ repertorio iberico del Canconiere N 871 di Montecassino. Musica e poesia alla corte aragonese di Napoli, Como-Pavia, Ibis, 2005, pp. 9-11.

4 "El contexto socio-cultural del Cuatrocientos ibérico había producido en efecto una nueva figura de poeta-literato o incluso de versificador aficionado contrapuesta a la arcaica del poeta-músico, característica del ámbito galaico-portugués. Los cancioneros cuatrocentistas atestiguan ya de forma evidente la circulación de textos no destinados al acompañamiento musical y el género cuenta con composiciones que nunca fueron musicadas" (Isabella Tomassetti, Mil cosas tiene el amor. El villancico cortés entre Edad Media y Renacimiento, Kassel, Edition Reichenberger, 2008, p. 118). 
rarias más o menos populares a nuevos acompañamientos musicales. En la estela de dicha perspectiva interdisciplinar, ofrezco aquí una primera exploración de los poemas atribuidos a Juan de Mena que figuran en el Cancionero Musical de la Colombina (SV1).

Se considera que el ms. 7-1-28, conservado en la Biblioteca Capitular de la Colombina de Sevilla, con el título — añadido en el siglo XVIIICantinelas vulgares puestas en música por varios españoles, pero conocido como Cancionero musical de la Colombina, fue compilado posiblemente alrededor de $1490^{5}$. Transmite una de las colecciones más célebres de la polifonía profana de finales del siglo XV, en la que resaltan músicos como Cornago y Triana, o poetas como Juan Rodríguez del Padrón, Juan de Mena e Iñigo López de Mendoza, marqués de Santillana.

Uno de los primeros estudiosos que examinaron el códice fue Higinio Anglés quien, en 1941, al revisar los repertorios musicales de la Biblioteca Colombina, reseñó la existencia de este cancionero, lamentando la falta de un pormenorizado estudio musicológico y de una edición crítica; en su descripción reproduce el incipit de los primeros versos, identificando 95 piezas, 89 con texto y música y 6 solo instrumentales ${ }^{6}$.

Puesto que SV1 no presenta una tabla, ya que nos ha llegado de forma incompleta, siendo acéfalo y mutilado de algunos folios, el primer obstáculo con el que los editores han tenido que enfrentarse reside precisamente en la identificación del número exacto de las composiciones poéticas ${ }^{7}$.

5 Por lo que se refiere a la fecha de redacción de SV1, véanse Higinio Anglés, La música en la Corte de los Reyes Católicos. Polifonía religiosa, I, Madrid, CSIC, 1941, pp. 103-104; Robert Stevenson, Spanish Music in the Age of Columbus, The Hague, Martinus Nijhoff, 1960, pp. 206-207; Miguel Querol Gavaldá (ed.), Cancionero musical de la Colombina (Siglo XV), Barcelona, CSIC, Instituto Español de Musicología, 1971, p. 22; Brian Dutton, Catálogo-Índice de la poesía cancioneril del siglo $X V$, Madison, 1982, p. 142; Jineen Krogstad, "La música y los cancioneros: 14801520", en Apéndice II de Dutton, 1982, pp. 275-276; Lola Pons Rodríguez, "La lengua en el Cancionero musical de la Colombina", Cancioneros en Baena. Actas del II Congreso Internacional Cancionero de Baena, ed. Jesús L. Serrano Leyes, I, Baena, M. I. Ayuntamiento de Baena, 2003, pp. 588-608. Sobre este cancionero, véase Rafael Bonilla Cerezo y Paolo Tanganelli, "El Cancionero musical de la Colombina [SV1]. Fenomenología de los errores privativos y algunas huellas en los cancioneros literarios", eHumanista, 38 (2018), pp. 915-926.

6 Higinio Anglés, op. cit., pp. 103-106.

7 Véanse Gertraut Haberkamp, Die weltliche Vokalmusik in Spanien um 1500, Tu- 
Tarea nada fácil considerando que los textos poéticos son fragmentarios, ya por la caída de algunos folios, ya por la tendencia de los músicos a reproducir solo los primeros versos de la cabeza y los de la mudanza.

Anglés, por lo que se refiere a las 89 composiciones citadas, no se dio cuenta de que algunas coplas añadidas sin música —en los espacios dejados en blanco durante una primera fase de radacción — en realidad son textos de diferentes autores. De hecho, SV1 parece transmitir asimismo los fragmentos de otras 17 composiciones copiadas sucesivamente (en los ff. $\left.2^{\mathrm{r}}-4^{\mathrm{r}}, 6^{\mathrm{r}}, 58^{\mathrm{r}}\right)$. Gavaldá y Haberkamp mantienen la misma numeración de Anglés, considerando dichos fragmentos como parte de las mismas composiciones a las que fueron ańadidos por otra mano. Por el contrario, Brian Dutton en El Cancionero del Siglo XV, aun no modificando la numeración tradicional establecida por los editores, asigna correctamente un número de identidad diferente a cada uno de estos fragmentos ${ }^{8}$.

Otros obstáculos que es preciso sortear afectan a la estructura y los criterios de redacción de SV1, ya que no se trata de un verdadero cancionero, sino de varios cuadernos musicales destinados o manejados por varios músicos. Gracias al cotejo con el resto de la tradición poética y a las fuentes bibliográficas reproducidas por Dutton, es posible determinar la autoría tan solo de un puñado de textos de $\mathrm{SV} 1^{9}$, entre los cuales figuran

tzing, Schneider, 1968; Miguel Querol Gavaldá, op. cit:; Brian Dutton, El Cancionero del siglo XV (c. 1360-1520), Salamanca, Universidad de Salamanca, 1990-1991, IV, pp. 288-301; José Sierra Pérez, José Carlos Gonsálvez Lara, Cancionero musical de La Colombina: cantinelas vulgares puestas en música por varios españoles (Siglo XV), Ed. facs., Madrid, Sociedad Española de Musicología. Asociación Española de Documentación Musical, 2006. En 1952, además, Robert Stevenson ya había publicado una edición parcial (32 textos) del Cancionero: Robert Stevenson, Cantinelas vulgares puestas en música por varios españoles, Lima, Pacific Press, 1952.

8 De estos, tres parecen textos completos: No devo dar culpa a vos (SV1-1-1); Bien sé que no me queréys (SV1-1-2); Pues con sobra de alegría (SV1-2 ${ }^{\text {bis }}$ ). Los demás son parciales: Pues que vuestra piedad (SV1-4-1); Pues no soys qual presumýa (SV1-4-2); Plázeme pues sé que sygo (SV1-4-3); En el serviçio de vos (SV1-4-4); Vuestros ojos que myraron (SV1-45); Él vos fizo sin enmyenda (SV1-4-6); Yo solo sea culpado (SV1-4-7); Dudando quyero moryr (SV1-4-8); Sienpre dyxe byen de vos (SV1-4-9); Quanto a que syento amor (SV14-10); Tan ásperas de sofryr (SV1-4-11); Byen sé cierto por maneras (SV1-4-12); Sy non ved por sus maneras (SV1-4-13); Vo buscar do so vençido (SV1-43-1).

9 Solo en una ocasión el copista introdujo el nombre del poeta Diego Tristán en la rúbrica de la canción de Triana No puedes quexar, Amor (SV1-28) "de Diego tristan triana el son". 
tres poemas de Juan de Mena. Los dos primeros con acompañamiento musical: Oya tu merçed y crea (SV1-12) y Porque más sin duda creas (SV127); el tercero, inserto en un espacio en blanco y sin acompañamiento musical, Vuestros ojos que myraron (SV1-4-5): es decir, el número 5 de los añadidos debajo de Gentil dama (SV1-4).

Oya tu merçed y crea figura en los ff. $17^{\mathrm{v}}-18^{\mathrm{v}}$ y es incompleto por la pérdida del f. 19 (=xxiii); de hecho, conserva solo los ocho primeros versos (4, 4...). Hay que señalar que la composición aparece como anónima también en las otras dos fuentes musicales que transmiten el texto en una versión de doce versos: el Cancionero musical de la Catedral de Segovia (SG1) y el Cancionero musical de Palacio (MP4) ${ }^{10}$; mientras que, en el resto de la tradición poética, se atribuye a Juan de Mena o Pedro Manrique un texto de veinte versos (con la única excepción del Cancionero de poesías varias, MP2, que reproduce la versión de doce versos de la tradición musical) ${ }^{11}$.

La pieza seguramente fue muy popular, ya que se conservan dos glosas de los siglos XV y XVI, compuestas respectivamente por Tapia y Diego Pegera, poetas cancioneriles que interpretan el texto de Mena en sentido religioso, como se indica en las rúbricas. Algunos versos, además, ya los había citado el Comendador Román, a finales del XV, en la Resurreción de Nuestro Señor Jesus Cristo ${ }^{12}$.

Aunque todavía no se haya acometido el cotejo de todos los apógrafos, la canción debió de difundirse a través de la melodía en la versión de doce

10 SG1= Segovia, Archivo de la Catedral, [sin llamada] Cancionero musical (c.1500), f. $217^{\mathrm{r}}(4,8) ; \mathrm{MP} 4$ = Madrid, Biblioteca de Palacio, ms. 1335: Cancionero musical de Palacio (c. 1498-1520), ff. 27v-28 $(4,8)$.

11 SA10 = Salamanca, Biblioteca Universitaria, ms. 2763 (dos mss. en uno c. 1495 y c. 1510), f. $146^{\mathrm{r}}(4,2 \mathrm{x} 8)$, "Cançion de juan de mena"; $12 \mathrm{MO}=$ Las ccc. del famosissimo poeta Juan de Mena: con otras xxiiij coplas y su glosa y la coronacion del mesmo poeta e otras cartas e coplas e canciones. Agora nuevamente añadidas, Sevilla, Jacobo Cronberger, 24.9.1517, f. 140v (4, 2x8), "Cancion de Juan de mena"; MP2 = Madrid, Biblioteca de Palacio, ms. 617: Cancionero de Poesias varias (c. 1560), $\mathrm{f}$. $165^{\mathrm{r}}(4,8)$, "Cançion de Dom pedro Manrrique Duque de nagera"; O 1552 = Las trezientas d'el famosissimo poeta Ivan de Mena, glosadas por Fernan Nuñez... Otras XXIII Coplas suyas, con su glosa. La Coronación, compuesta y glosada por el dicho Iuan de Mena. Tratado de vicios y virtudes, con otras Cartas y Coplas y Canciones suyas, Anvers, Juan Steelsio, 1552, ff. 262 ${ }^{\mathrm{v}}-263^{\mathrm{r}}$ (4, 2x8), "Cancion de Juan de Mena”.

12 Comendador Román, Coplas de la pasión con la resurrección, ed. Giuseppe Mazzocchi, Firenze, La Nuova Italia, 1990; Diego Pegera, Consuelo de los naçidos [ID 4351] (vv. 1-12). 
versos, dispuestos en tres redondillas (en SV1, MP4, SG1, MP2) ${ }^{13}$. En cambio, como acabamos de recordar, las otras fuentes literarias (SA10b, 12MO, O 1552) conservan dos redondillas más entre la primera (Oya tu merçed y crea...) y la segunda estrofa (Pues tu vista me salvó... $)^{14}$.

Desde un punto de vista temático, la pieza desarrolla el motivo cancioneril del poder regenerador de la contemplación de la amada ${ }^{15}$. Presenta los recursos retóricos característicos del usus scribendi de Mena, como el empleo de la hipérbole sacro-profana, basada en el sentido teológico del verbo perderse (vv. 3-4, "ombre que tu gesto vea / nunca puede ser perdido"); el apóstrofe (v. 2, “jay de quien nunca te vido!”), el hipérbaton (vv. 7-8, "pues que, señora, de muerte / tu figura me libró") y numerosas figuras de repetición: la anáfora del pronombre de segunda persona de singular ("tú", "te"), marca retórica de toda la canción (vv. 1-3, 5-6, 8, 11); la repetición de términos fonéticamente similares en los vv. 5-7 ("salvó", "saña”, "señora”) y, sobre todo, el políptoton de los vv. 2, 3, 5, 11 ("vido", "vea”; "vista”, "vea"). De hecho, toda la composición resulta dominada por la reiteración del verbo ver y de sus derivados, que figuran en todas las coplas (el arcaísmo "vido" en el v. 2 -y no hay que olvidar que los arcaísmos constituyen una peculiaridad de la lengua de Mena_- el subjuntivo "vea" del estribillo; y el término "vista" del v. 5). En resumidas cuentas, el políptoton subraya el motivo central de la canción de Mena y enlaza retóricamente, a través de un sistema de reiteraciones internas, una copla con otra ${ }^{16}$.

13 Reproduzco la versión de doce versos de MP4a-13: "Oya tu merçed i crea, / jay de quien nunca te vido, / onbre que tu gesto vea / nunca puede ser perdido! / Pues tu vista me salvó, / çese tu saña tan fuerte, / pues que, señora de muerte, / tu figura me libró. / Bien dirá qualquier que sea, / sin temor de ser vençido, / [jonbre que tu gesto vea / nunca puede ser perdido!]”. En al transcripción de los textos se han adoptado los siguientes criterios: se introducen los signos diacríticos, se desarrollan las abreviaturas, se resuelve la alternancia $u / v$, se señalan entre paréntesis cuadrados las lagunas del texto.

14 " [...] ya la tu sola virtud, / fermosura sin medida, / es mi todo vien y bida; / con esfuerço de salud, // quien tu vista ver desea / fablará no enfingido, / ¡onbre que tu gesto vea / nunca puede ser perdido! [...]".

15 Cfr. Miguel Ángel Pérez Priego, "Oya tu merced ycrea”, en Juan de Mena, Obra lírica, Madrid, Alhambra, 1979, pp. 75-76; Carla de Nigris, "Oya tu merçed y crea", en Juan de Mena, Poesie minori, Napoli, Liguori, 1988, pp. 294-296.

16 Cfr. María Rosa Lida de Malkiel, Juan de Mena. Poeta del prerrenacimiento español, México, Colegio de México, 1950, pp. 159-230; Miguel Ángel Pérez Priego, op. cit., pp. 28-37; Carla de Nigris, op. cit., pp. 41-63. 
Por lo que se refiere al segundo texto de Mena, Porque más sin duda creas

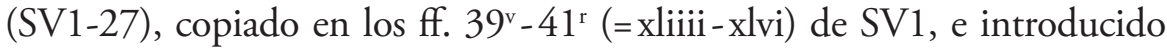
por una rúbrica con el nombre del músico "Cornago", el amanuense reproduce una composición de catorce octosílabos $(5,9)$. En este caso, contamos solo con otro testimonio literario, el del Cancionero de Herberay (LB2-54) ${ }^{17}$.

Se trata de una canción que versa sobre el motivo de la imprecación amorosa. Empieza con un duro reproche a la amada — que el poeta condena a sufrir su mismo tormento: amar sin ser correspondida- a través de la intensa aliteración del v. 3 ("dete dios tan triste vida"); mientras que enfatizan la condena el encabalgamiento y la asonancia de los vv. 4-5 ("que ames y nunca seas / $a \mathrm{~m} a \mathrm{~d} a$ ni bien querid $a$ "). En la copla central el poeta explica la razón de su reprensión, retomando el concepto expresado en el hipérbaton del primer verso ("Porque más sin duda creas"), a través de la referencia fónica sugerida por el políptoton de los vv. 1, 7 “creas"/"creerás". Solo viviendo su misma "vida” la amada podrá entender el "tormento desigual” que causa al poeta.

Finalmente, en la última copla, enlazada a la anterior por el juego fónico del políptoton y de la aliteración de los vv. 9-11 ("que sin mereçer me das / pues que muerte me deseas / sin tenerla mereçida"), se corrobora la condena inicial. Pero la repetición del estribillo resulta enriquecida por la variatio, ya que los versos no se calcan de manera idéntica. De esta forma se genera en los tres versos finales un denso juego de repeticiones que recuerdan antitéticamente los últimos versos de la copla inicial. Nótense, en particular, la antítesis del v. 4 ("que ames y nunca seas") y del v. 13 ("que ames e siempre seas"), y una vez más el contraste entre el v. 5 ("amada ni bien querida”) y el v. 14 ("desamada y mal querida”): oposición realzada mediante la antítesis "bien"/"mal” y, sobre todo, de la paronomasia "amada"/“desamada", que potencia ulteriormente el juego de enlaces y duplicaciones.

Por lo que concierne a Vuestros ojos que myraron (SV1-4-5), tema principal de nuestro estudio, aparece copiada en el folio $6^{\mathrm{r}}$ de SV1 junto con otras coplas reproducidas en dos columnas, añadidas por una mano diferente respecto a la que trasladó el villancico anterior. De hecho, reproduce los

17 LB2-54 = London, British Library, ms. Add. 33382: Cancionero de Herberay o de Rennert (c. 1465), f. 78 $8^{\text {rv }}(5,9)$, "Johan de Mena". LB2 y SV1 transmiten el mismo texto. Por lo que atañe a la tradición indirecta, la primera copla (vv. 1-4) de Porque más sin duda creas fue citada en una canción anónima, Donzella desconoçida [ID 1880]. 
primeros ocho versos $(4,4 \ldots)$ de esta canción junto con fragmentos de otras doce composiciones poéticas de diferentes autores sin la parte musical.

No conocemos la melodía de Vuestros ojos que myraron; sin embargo, no es arriesgado suponer que también esta composición de Mena, como las otras dos piezas de SV1, se haya difundido de forma cantada.

Vuestros ojos cuenta con otros dos testimonios literarios que se repiten en el Cancionero de Herberay (LB2-57, LB2-82); transmiten la versión completa del poema, de doce versos $(4,8)^{18}$.

\section{LB2-57 (f. $79^{\text {rv }}$ ) \\ Johan de Mena \\ LB2-82 (f. $91^{\mathrm{v}}$ ) otra \\ SV1-4-5 (f. $\left.6^{\mathrm{r}}\right)$}

Vuestros oios que miraron, con tan discreto mirar, firieron e non dexaron en mí nada por matar.

$+$

$\underline{Y}$ aun ellos no contentos de mi persona vençida, dan a mí tales tormentos

8 que me tormenta la vida: después que me sojuzgaron e no con poquo pensar, firieron e no dexaron 12
Vuestros oios que miraron, con tan discreto mirar, firieron e non dexaron en mí nada por matar.

Ellos aun no contentos de mi persona vençida, me dan atales tormentos que atormentan mi vida: y después que me sojuzgaron con tan discreto mirar, firieron e no dexaron en mí nada por matar. g Vuestros ojos que myraron, con tan discreto myrar, $\underline{\text { fueron }}^{19}$ e non dexaron en mý nada por matar.

9 $\underline{Y}$ aun ellos no contentos de my persona vençida, dame tan grandes tormentos que me atormenta la vyda.

Desde el punto de vista temático, Vuestros ojos es una canción que desarrolla, igual que Oya tu merçed, el motivo de la vista. Pero en este caso la composición se cierra en la mirada de la amada, que tiene consecuencias trágicas: a pesar de definirlo como "discreto", su mirar (v. 2) es portador de muerte. "El motivo de los ojos homicidas, típico de la lírica tradicional" 20 , es introducido en la primera copla a través de un juego

18 LB2 reproduce la primera en el f. $79^{\text {rv }}$ con el epígrafe "Johan de Mena"; la segunda en el f. $91^{v}$ con el de "otra". En la transcripción del f. $79^{\text {rv }}$ el copista ha reproducido en un primer momento solo los primeros cuatro versos de la canción. Los vv. 5-12, de hecho, han sido añadidos sucesivamente, con un cuerpo más pequeño, en el margen derecho del mismo folio, por la misma mano. Además, un signo (probablemente una cruz) indica la necesidad de integrar el texto anotado en el margen.

19 No me detengo en esta ocasión enel examen de la varia lectio. Solo evidencio las divergencias.

20 Miguel Ángel Pérez Priego, op. cit., p. 69. 
de repeticiones que permea toda la composición. Puede notarse, en esta primera copla, la combinación del políptoton y de la paronomasia, enfatizados por su colocación en posición de rima, que afecta a tres versos (vv. 1-4, "Vuestros ojos que myraron / con tan discreto mirar / firieron y no dexaron / en mi nada por matar"), con el fin de manifestar la estrecha relación entre mirar y matar.

En la segunda copla, se insiste en los efectos de la mirada de la amada, que podría tildarse como «sin piedad», ya que ella, a pesar de que el poeta esté ya rendido (v. 6, "de mi persona vençida"), sigue infligiéndole con su mirada "tan grandes tormentos" (v. 7). Obsérvese que en esta segunda copla se resalta, a través de la obsesiva repetición de los adjetivos y de los pronombres de primera persona ("mi", "me"), justo la figura doliente del poeta. No sería descabellado considerar todo el poema como un proceso de reconstrucción de la lenta y dolorosa muerte que la mirada de la amada le causa.

En la estrofa final se describe la capitulación definitiva del amante, literalmente sometido por la mirada de la mujer. Esta última copla enlaza retóricamente con el resto de la composición gracias a la parcial reiteración del estribillo, y, sobre todo, en virtud de la aliteración de la $m$ en el último verso (LB2, v. 12, "en mi nada por matar"), auténtica marca retórica de toda la canción, ya que la nasal se encuentra prácticamente en cada verso.

Me parece oportuno reflexionar sobre la relación entre Vuestros ojos de Mena, las demás coplas añadidas en el mismo folio $6^{\mathrm{r}}$ y la composición Gentil dama bajo la cual fueron insertadas.

Por lo que se refiere a Gentil dama (SV1-4), se trata de un villancico transcrito con música en los ff. $5^{\mathrm{v}}-7^{\mathrm{r}}$ de SV1, en el que falta la copla final $(3,4 \ldots)$. Aquí el copista reproduce un texto de siete versos. Transmite el poema también otra fuente musical, MP4 (a-23) en los ff. $36^{\mathrm{v}}-37^{\mathrm{r}}$, donde es introducido por la rúbrica "Cornago". El copista transcribe el texto completo de diez versos $(3,4,3)$, en el que la tercera copla, de tres versos, repite parcialmente el esquema de rimas del estribillo (ebb) y de manera idéntica su último verso ${ }^{21}$.

Desde el punto de vista temático, el villancico desarrolla el mismo motivo de la vista de la amada y de sus efectos. Como se puede no-

21 En cuanto a la música transmitida por los dos cancioneros, la melodía es la misma. 
tar, ya tenemos un primer punto en común con la canción de Mena Vuestros ojos, relación reforzada por la presencia en las dos composiciones de la misma palabra clave: el verbo mirar. En el villancico el motivo de la vista es subrayado, además, por la cita del refrán "sino ver y desear” (v. 3), que gozó de una larga fortuna en la poesía española, tanto de tradición oral como literaria. Según algunos críticos, esta frase tendría un origen culto, que se remontaría a la poesía trovadoresca y constituye un tecnicismo que volvemos a encontrar en muchos poemas ${ }^{22}$.

En la segunda copla, el anónimo poeta describe las virtudes que su mirada descubre en la mujer: "beldat" (v. 5) y "bontat" (v. 7); cualidades que, sin embargo, no logran salvarle de su "fin temprano" (MP4a-23, v. 8), causado por el "ver y desear" (MP4a-23, v. 10).

A la luz de estas correspondencias, arriesgamos que los versos de Mena añadidos bajo Gentil dama (SV1-4) pudieron constituir una alternativa a la mudanza del villancico, ya que Vuestros ojos y Gentil dama, además de ser afines musicalmente, presentan otros puntos de contacto. Por lo que se refiere a la temática de la vista ya mencionada, es necesario precisar que resulta enfatizada en ambos poemas por la repetición del verbo "mirar", y en ambos casos a través del políptoton: por un lado, los vv. 2 y 5 de SV1-4 ("otro bien de vos mirar [...] / mirando vuestra beldat"); por el otro, los primeros dos versos de SV1-4-5 ("Vuestros ojos que miraron / con tan discreto mirar").

Otro elemento que podría conectar Gentil dama y Vuestros ojos es el motivo de los efectos de la vista de la amada. Aunque el sujeto de mirar es diferente en los dos poemas (los ojos en el caso de Mena, el amante en Gentil dama), en ambos casos el destino del poeta es la muerte, como se recuerda en la primera y en la última copla de Vuestros ojos ("Vuestros ojos [...] / firieron y non dexaron / en mi nada por matar", vv. 1-4; 11-12) y en la tercera de Gentil dama ("ansí que mi fin tem-

22 Gema Vallín y María Isabel Toro Pascua, "Lírica culta, lírica tradicional: intercambios («Ver y desear»: un villancico popular de origen trovadoresco", en La literatura popular impresa en España y en la América colonial: formas y temas, géneros, funciones, difusión, historia y teoría, dir. Pedro Manuel Cátedra García, Salamanca, Seminario de Estudios Medievales y Renacentistas-Instituto de Historia del Libro y de la Lectura, 2006, pp. 169-189. 
prano / non lo tiene de causar / sino ver y desear”, MP4a-23, vv. 8-10). Al juntar el texto de Mena al villancico, se crea un juego de contrastes entre las consecuencias de la respectiva mirada de los amantes (letal en ambos casos) y la imagen que se da de la dueña: sin piedad en el caso de Mena ("y aun ellos no contentos / de my persona vençida", vv. 5-6); caracterizada por la bondad en el villancico ("notando vuestra bondat", v. 7).

No menos patentes son las afinidades en la vertiente retórica. Además del ya mencionado políptoton, ambos textos comparten el empleo de la rima aguda: "mirar"/“desear" en el villancico, y "mirar" / "matar" en los versos de Mena. Añádase la presencia de la pareja (no forzosamente de sinónimos) en los vv. 3, 6 de Gentil dama ("syno ver y desear", "se destruye y se desfaze") y en los vv. 5 y 11 de Vuestros ojos ("fireron y non dexaron"); la paronomasia en los vv. 5 y 7 del villancico ("beltad" / "bondat") y en los vv. 2-4 del texto Mena ("myrar” / "matar"); y la anáfora interna del posesivo y del pronombre de segunda persona plural en los vv. 2, 5 y 7 de Gentil dama ("otro bien de vos mirar", "mirando vuestra beldat", "notando vuestra bondat") y la del pronombre y del adjetivo de primera persona singular ("mi" / "me"), ya citada, en los vv. 4, 6, 7, 8, 9 y 12 de Vuestros ojos.

Como se puede apreciar, las relaciones entre las dos composiciones son abundantes y se antoja por lo tanto plausible, desde el punto de vista métrico y temático, la hipótesis de que este texto de Mena pudiera cantarse como mudanza de Gentil dama.

A este respecto, y considerando ahora las semejanzas métrico-temáticas, parece imprescindible detenerse también en las doce coplas añadidas en el f. $6^{\mathrm{r}}$, y abundar en el examen de su relación con el villancico de Cornago. 


\section{ff. $5^{\mathrm{v}}-7^{\mathrm{r}}$ : Cornago, Gentil dama}

SV1-4

$[\mathrm{S}]$ $\mathrm{T}$

C

Gentil dama non se gana Gentil dama non se gana... Gentil dama non se gana... otro bien de vos mirar, syno ver y desear.

4 El deleyte que se faze, mirando vuestra beldat, se destruye y se desfaze, notando vuestra bondat;

El deleyte que se faze... El deleyte que se faze... se destruye y se desfaze... $\quad$ se destruye y se desfaze...
MP4a-23
$[\mathrm{S}]$
Tenor
Gentil dama non se gana...
Gentil dama non se gan
otro bien en vos mirar,
sino ver i desear.
4 El deleite que se faze,
El deleite que se faze...
El deleite... mirando vuestra beldad, se destruye ...
notando vuestra bondad;
8 ansí que mi fin tenprana non lo tiene de causar sino ver y desear.

Gentil Contra

\section{folio $6^{\mathrm{r}}$ : coplas añadidas}

1 I Pues que vuestra piedad para mí es tan escura, tornad my libertad, con que busque my ventura [...]

2 Pues no soys qual presumýa "ny yo soy quyen ser solía". Yo vos guardé lealtad quando en vos sentý verdad; mas, agora, perdonad, \& sabed de parte mýa... [...]
[...] Él vos fizo sin enmyenda de gentyl persona cara e, su mando sin contyenda, qual jano non vos pintara [...]

g Yo solo sea culpado, 7 vos queryendo my querer, $\&$ pensad mayor pecado ser matar que ofender [...]

I Dudando, quyero moryr, 8 no dexando de escrevir my mote "ver y creer" [...] 
3 [...] 9 Plázeme, pues sé que sygo lo que virtud me rrequiere; desplázeme que fatygo my querer que no lo quyere [...]

4 En el serviçio de vos toda my vida me fundo, por lo qual no yero al mundo, ny mucho menos a Dyos. [...]

5 Vuestros ojos que myraron, con tan discreto myrar, fueron e non dexaron en mý nada por matar. gY aun ellos no contentos de my persona vençida, dame tan grandes tormentos que me atormenta la vyda [...]
Sienpre dyxe byen de vos, desde que me conocistes; tal paresca yo ante Dyos qual sienpre me parecistes [...]

g Quanto a que syento amor, $\&$ de como sé que duele, no syento pena mayor, ny que más me desconsuele [...]

I Tan ásperas de sofryr son mys angustyas y tales que de mys esquyvos males es el rremedyo moryr [...]

Byen sé cierto por maneras, avnque soy mal adivyno, que no dyga el buey al vino "no te quyero ny me quyeras"

13 Synon ved por sus maneras,

según su beber contyno;

sy dacá quýtame el vino

$[\ldots .$.$] que y [\ldots]$ uet $[\ldots]$ vino $^{21}$

Para siete de estas coplas individuadas por Dutton no hemos encontrado otros testimonios que nos permitan reconstruir la composición poética completa: Pues que vuestra piedad (n. 1); Pues no soys qual presumýa (n. 2); Dudando quyero moryr (n. 8); Sienpre dyxe byen de vos (n. 9); Quanto a que syento amor (n.10); Byen sé cierto por maneras (n. 12); y Sy non ved por sus maneras (n. 13). Se trata principalmente de redondillas de octosílabos con rima abab, con la excepción de Byen sé cierto (12) y Sy non ved (13) que adoptan el esquema abba y de Pues no soys qual presumýa (2), que es una sextilla de octosílabos con esquema de rimas aabbba. En cuanto a SV1-4-12 y SV1-4-13 hay que considerarlos un único poema, como sugieren el esquema métrico, el tema tratado y sobre todo la presencia de un signo, una cruz, al final y al principio de las dos coplas, con la que se indica cómo leer la composición.

23 Parcialmente cortado. 
Dichas coplas tratan típicos motivos cancioneriles, como la ausencia de piedad por parte de la amada (n. 1); la lealtad del amante (n. 2); el tema de la vista (n. 8); la alabanza de la amada (n. 9); las penas sufridas por el poeta (n. 10) y, probablemente, hay "una versión burlesca de una pieza de amor cortés"24 (nn. 12 y 13). Todas poseen afinidades temáticas con Gentil dama. En muchos casos se repiten los mismos términos ("ver" en n. 8 y n. 13; "vos" en n. 2, n. 9); o se usa el mismo tipo de rima ("piedad" / "libertad" en la n. 1; y "lealtad" /"verdad" / "perdonad" en la n. 2).

Por lo que concierne a las cinco cinco coplas restantes -Plázeme pues sé que sygo (n. 3); En el serviçio de vos (n. 4); Él vos fizo sin enmienda (n. 6); Yo solo sea culpado (n. 7); y Tan ásperas de sofryr (n. 11) - se encuentran también en otras fuentes, tanto literarias como musicales. También en estos casos se pueden detectar algunas relaciones métrico-temáticas con el villancico puesto en música por Cornago.

La copla número 3, Plázeme pues sé que sygo, se corresponde con la mudanza (4vv.) de la canción Tanto quanto me desplaze ${ }^{25}$. Es necesario precisar que conocemos la música de este poema, ya que en el f. $19^{\mathrm{r}}$ del mismo Cancionero musical de la Colombina se reproduce solo el incipit de la canción bajo la voz Contra, (SV1-13). Gentil dama y Plázeme pues sé que sygo son afines desde el punto de vista temático, ya que en esta copla añadida el poeta se declara feliz de seguir "lo que virtud [...] requiere" (v. 2), es decir, amar a esta "Gentil dama” sin obtener nada en cambio, "sino ver y desear". Se encuentra, además, una afinidad fónica entre el v. 6 del villancico ("se destruye y se desfaze") y el inicio del v. 3 de la copla añadida ("desplázeme que fatigo").

En el serviçio de vos (n. 4) se corresponde con la primera copla (4 vv.) de una canción anónima, transmitida, en su forma completa de doce versos $(4,8)$, por otro cancionero musical y por una fuente literaria ${ }^{26}$. Desarrolla la temática del servicio de amor, subrayada por el empleo de la hipérbole sagrada ("por lo qual no yero al mundo / ny mucho menos a Dyos", vv. 3-4). Resulta afín al villancico puesto en música, ya que este servicio pue-

24 Lola Pons Rodríguez, op. cit., p. 591. Es muy difícil establecer el tema de estos dos fragmentos, ya que los versos finales han sido cortados.

25 Figura también en PN4-10b = Paris, Bibliothèque National, ms. Esp. 226 (c. 1490), f. $35^{v}(3 \times 4)$, "otra".

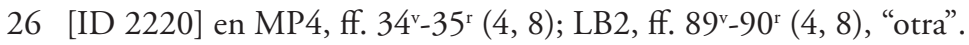


de ser dirigido a esta "Gentil dama", como prueba la repetición en ambos textos del pronombre "vos" ("otro bien de vos mirar", SV1-4, v. 2; "En el serviçio de vos", SV-4-4, v. 1).

Él vos fizo sin enmyenda (n. 6) constituye la segunda copla (4vv.) de una canción que el marqués de Santillana compuso para la reina Isabel de Portugal y que empieza con Dios vos faga virtuosa. Esta canción del marqués está formada por siete coplas de tres y cuatro octosílabos ${ }^{27}$.

La coplilla añadida en SV1 versa sobre la beldad de la amada y resulta, por lo tanto, muy próxima a Gentil dama, en la que se cita la "beldat" de la mujer. Además, en ambas composiciones figura el pronombre "vos" dirigido a la amada.

La misma situación se da en la copla Yo solo sea culpado (n. 7), que, en realidad, constituye la mudanza (4vv.) de una canción de Carvajal, poeta activo en la segunda mitad del siglo XV, y que empieza por Si dezís que vos ofende. El texto de SV1 figura también en otras dos fuentes literarias, que transmiten la versión completa de doce versos ${ }^{28}$. También en este caso hay relaciones con el texto puesto en música por Cornago, ya que el "querer" (v. 2) del poeta puede atribuirse a la "Gentil dama", a la que pide que no se ofenda por este sentimiento suyo, ya que "matar" (v. 4) sería un pecado mayor con respecto al amor. Además, la común rima aguda de las dos composiciones ("mirar" / "desear", vv. 2-3 en Gentil dama, y "querer" I "ofender", vv. 2, 4, en Yo solo sea culpado). De nuevo (como en la n. 6, El vos fizo...) encontramos el pronombre "vos" dirigido a la amada: "Él vos fizo sin enmyenda"(n. 6, v. 1); "vos queryendo my querer" (n. 7, v. 2).

Finalmente, Tan ásperas de sofryr (n. 11) corresponde a la primera copla (4 vv.) de una composición transmitida por otra fuente literaria en la versión completa de doce versos ${ }^{29}$. La canción tuvo que ser muy popular,

27 [ID 0316] se transmite en forma completa (24vv.) en otras cuatro fuentes literarias: MH1 = Madrid, Biblioteca Real Academia de la Historia, 2 Ms 2: Cancionero de San Román (c. 1454), f. $111^{\mathrm{r}}$ (3, 3x7), "otra"; SA8 = Salamanca, Biblioteca Universitaria, ms. 2655: Obras de Santillana (c. 1456), ff. 243" $-244^{\mathrm{r}}$ (3, 3x7), "otra"; SA10, f. 134' (3, 3x7); MN8 = Madrid, Biblioteca Nacional, ms. 3677: Obras de Santillana (c. 1700), f. $213^{\mathrm{v}}(3,3 \times 7)$.

28 [ID 0605]: se encuentra en MN54 = Madrid, Biblioteca Nacional, ms. Vitrina 177: Cancionero de Stúniga (c. 1462), f. 129v(4, 8), "Carvajales cançion suya"; LB2, f. $78^{\mathrm{r}}(4,8)$, "Rey daragon a lucrecia".

29 [ID 0862] en LB2, ff. 88 $89^{\mathrm{v}}$, "otra". 
ya que contamos con dos glosas que se remontan a la segunda mitad del siglo XV: una de Francisco de Miranda y otra de Fray Íñigo de Mendoza, dos poetas que interpretaron de modo diverso la canción: el primero desde una perspectiva profana, el segundo a lo divino. Demuestran conocer la canción otros poetas de finales del siglo XV y de principios del XVI, que citan algunos versos en sus composiciones. Entre ellos, resaltan los nombres de Guevara y Pinar, cuyos textos asimismo presentan reminiscencias de otras piezas reproducidas en $\mathrm{SV} 1^{30}$.

También esta copla añadida podría ser utilizada como alternativa a la mudanza de Gentil dama, ya que, desde el punto de vista temático, no sería extrańo que la vista de la amada provocara en el poeta "angustias” (v. 2) "tan ásperas de sofryr" (v. 1); y, como en el villancico, la única solución posible para el tormento del poeta sería la muerte ("así que mi fin temprano", MP4a-23, v. 8; "es el rremedyo morir", SV1-4-11, v. 4).

A la luz de estos datos, se podría columbrar que todas estas coplillas, que pertenecen a composiciones poéticas distintas, podían cantarse como alternativa a la mudanza del villancico Gentil dama ${ }^{31}$. Corrobora esta hipótesis el hecho de que, al menos en los casos examinados donde se conoce el texto completo, el copista reproduce casi siempre la mudanza de la canción. Es lo que ocurre en Plázeme pues sé que sigo (n. 3), Él vos fizo sin enmienda (n. 6) y Yo solo sea culpado (n. 7); solo en dos ocasiones se transcribe la primera copla: En el serviçio de vos (n. 4) y Tan ásperas de sofryr (n. 11) y, finalmente, en el caso de Vuestros ojos que myraron (n. 5) se transcriben la primeras dos coplas de la canción.

En conclusión, SV1 confirma que los poemas menores de Mena tuvieron una amplia difusión cantada. Lo demuestran no solo las dos piezas

30 Francisco de Miranda, Quant brauas son en ferir [ID 2115] (vv. 1-12); Fray Íñigo de Mendoza, Yo siento dentro vn ferir [ID 8106] (vv. 1-12); Guevara, Recontar si mal senti [ID 0859] (v. 1); Pinar, Tome vuestra magestad [ID 6637] (v. 1); Diogo Marquam, Por verdes em que cuidado [ID 5211] (vv. 1-4); Coudel moor, Foy graça notaya bem [ID 7684] (vv. 4, 8).

31 M. Q. Gavaldá, aunque no las considera como fragmentos de textos de diferentes autores, sino como parte del poema Gentil dama, afirma que "el resto de las estrofas se canta con la música de la primera copla. El estribillo se repetía probablemente después de varias coplas, a discreción del maestro de capilla. Es así como se acostumbraba a interpretar en el caso que quisieran cantar todas las coplas o varias, cuando éstas eran muchas" (Miguel Querol Gavaldá, op. cit., p. 38). 
con acompañamiento musical, Oya tu merçed y crea y Porque más sin duda creas, sino también el fragmento sin música, Vuestros ojos que myraron, por las sustanciales afinidades temáticas, métricas y retóricas que la vinculan al villancico de Cornago. 